\title{
Primary energy consumption for insulating
}

\author{
Maksim Terekh ${ }^{1, *}$, and Darya Tretyakova ${ }^{1}$ \\ ${ }^{1}$ Peter the Great St. Petersburg Polytechnic University, St. Petersburg, Russian Federation
}

\begin{abstract}
In this article a mathematical model for thermal protection level analysis is developed. It is based on the consumption rate of primary energy. It allows to calculate the relevant thickness of the selected insulation material under any climatic and economic conditions with any constant layers of building envelope taken from structural considerations. The key factors influencing the model are also evaluated. The main factors to influence the energy model are the region degree-days and the energy consumption rate for the production, transportation and installation of the insulation material. The following results were reached: this approach requires the data, which sometimes has no public access, provides us with an objective assessment criteria when comparing the level of building thermal protection in different countries.
\end{abstract}

\section{Introduction}

Energy efficiency is one of the key characteristics of modern construction, reflecting the rational use of energy resources and optimizing the amount of energy used to maintain a constant level of energy supply. The desire for the construction of buildings with a high level of energy efficiency is easy to explain by a will to create comfortable living conditions for people despite the resources scarcity and cost of energy (EU countries), or their significant expenditure in harsh climatic conditions (RF), which is also accompanied by an increase in the cost of buildings operating.

The main parameter of energy efficiency is the thermal resistance of the structure, the value of which depends on the sanitary and hygienic conditions of the premises and the cost of buildings operating.

A few studies went deeper in the investigation of buildings thermal parameters.

L. Danilevski and S. Danilevsky have developed an algorithm of determination of buildings thermophysical characteristics [1].

Constructive and technological ways of thermal resistance increasing was covered by E. Statsenko, A. Ostrovaia, T. Musorina, M. Kukolev, M. Petritchenko [2].

T. Kisilewicz has carried a research on the effect of thermal insulation overheating [3].

There are the normative values of thermal resistance established for each type of climatic conditions defined by region, which are used as the lower limit. This normative value can be achieved in various ways.

An issue of meeting the requirements of current standards in the designing and calculation processes was raised in a few articles observed [4-,7].

\footnotetext{
* Corresponding author: m_terekh@mail.ru
} 
A research of A. Gorshkov, N. Vatin, P. Rymkevich, O. Kudrevich contains a developed mathematical mode for evaluating the discounted payback period which could be widely used for construction evaluation purposes [8].

The Life-Cycle Cost analysis model was studied in the researches of L. Aditya, T. Mahlia, B. Rismanchi, H. Ng, M. Hasan, H. Metselaar, O. Muraza, H. Aditiya and also covered by L. Zhang, Z. Liu, C. Hou, J. Hou, D. Wei, Y. Hou by application of DeST energy simulation software $[9,10]$.

A question of engineering systems economical rating is covered by $\mathrm{O}$. Averianova in her article [11].

Several works were aimed at the study of the way that different attributes influence the energy cost [12] and the housing prices in general [12,14,15].

A few articles consider economically optimum insulation thickness of building construction affected by extreme climatic conditions of Asian regions [16-19].

As it was derived from the analysis of economic way of assessment (table 1), sometimes it is not applicable due to different economic conditions.

Table 1. Economic approach calculations

\begin{tabular}{|c|c|c|c|}
\hline City & $\begin{array}{c}R_{n}, \\
\frac{m^{2} \cdot{ }^{\circ} \mathrm{C}}{W}\end{array}$ & $\begin{array}{c}R_{o p t}, \\
\frac{m^{2} \cdot{ }^{\circ} \mathrm{C}}{W}\end{array}$ & $\Delta R, \%$ \\
\hline St. Petersburg & 3.06 & 3.44 & 12.41 \\
\hline Moscow & 3.06 & 3.54 & 15.68 \\
\hline Novosibirsk & 3.64 & 3.54 & -2.75 \\
\hline
\end{tabular}

This paper covers the way of thermal protection level analysing using the amount of primary energy.

\section{Methods}

\subsection{Energy approach to calculating the optimal thickness of the insulating layer}

Since the cost of thermal energy and materials differs greatly even within one country, then to assess the energy efficiency of building envelopes, we consider the costs of fuel and energy resources for their construction and operation.

Total energy costs can be calculated as:

$$
W=W_{c}+W_{e x} \cdot T
$$

where $W_{c}$ - the amount of fuel and energy resources needed to create structures including the costs of production, installation and transportation which is called primary energy.

$W_{e x}$ - annual need for fuel and energy resources for exploitation - operational energy;

$T$ - the period of time for which the operational needs for fuel and energy resources are taken into account, equals to the lifetime of structures (buildings). 


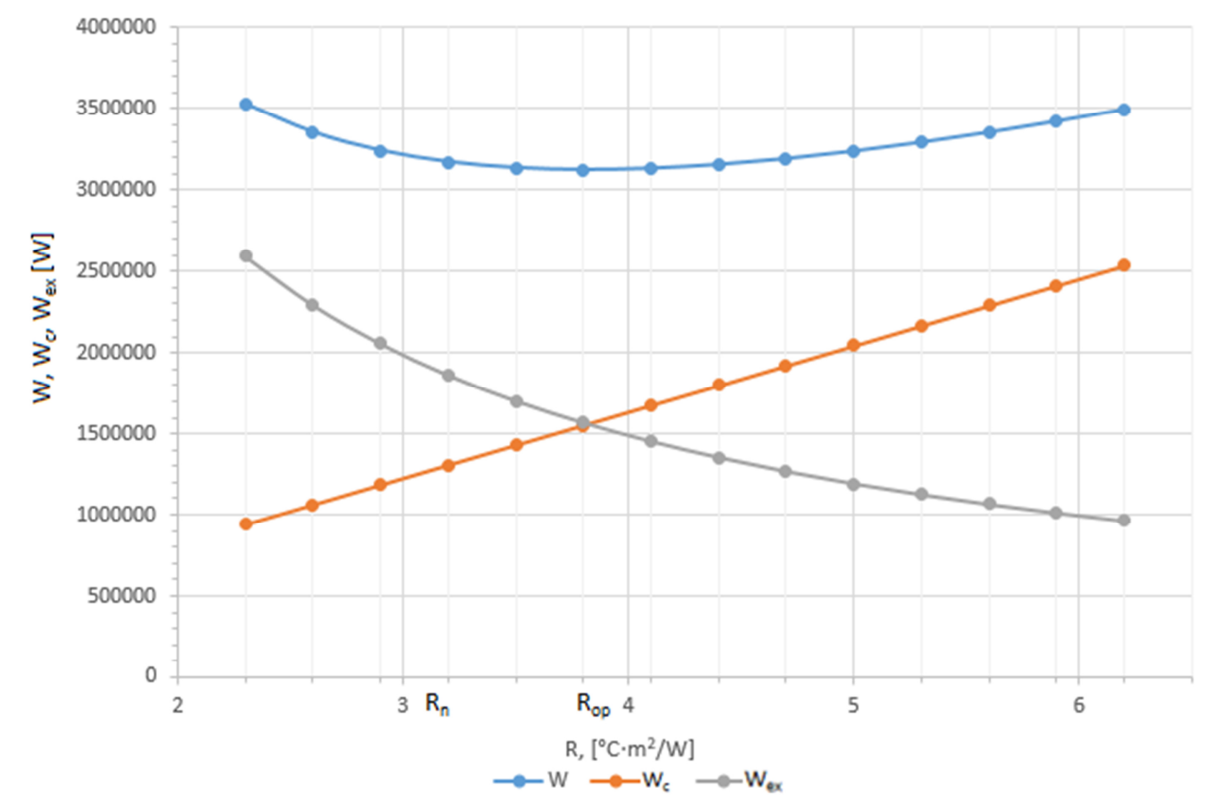

Fig.1. Change in total energy costs depending on thermal resistance R.

The amount of primary energy including the costs of production, installation and transportation:

$$
W_{\mathrm{c}}=W_{p}+W_{i}+W_{t r}
$$

where $W_{p}$ are the fuel and energy costs of structure production;

$W_{i}$ are the fuel and energy costs of structure installation;

$W_{t r}$ are the fuel and energy costs of structure transportation.

Substituting with the unit costs gives:

$$
W_{\mathrm{c}}=A_{p} \cdot m+A_{t r} \cdot m+A_{i} \cdot m
$$

where $A_{p}$ are the unit costs for production of $1 \mathrm{~kg}$ of insulation, $\frac{\mathrm{W}}{\mathrm{kg}}$;

$A_{t r}$ are the unit costs for transportation of $1 \mathrm{~kg}$ of insulation, $\frac{\mathrm{W}}{\mathrm{kg}}$;

$A_{i}$ are the unit costs for installation of $1 \mathrm{~kg}$ of insulation, $\frac{\mathrm{W}}{\mathrm{kg}}$;

$m$ is the mass of the insulation material, $\mathrm{kg}$.

Evaluating for $1 \mathrm{~m}^{2}$ :

$$
W_{\mathrm{c}}=\delta \cdot \rho \cdot\left(A_{p}+A_{t r}+A_{i}\right)
$$

where $\rho$ is the insulation material density, $\frac{\mathrm{kg}}{\mathrm{m}^{3}}$;

$\delta$ is the insulation layer thickness, $\mathrm{m}$.

Annual need for fuel and energy resources for exploitation of $1 \mathrm{~m}^{2}$ of a structure can be calculated as:

$$
W_{e x}=\frac{\left(t_{\text {in }}-t_{\text {ext }}\right) \cdot n \cdot m \cdot z}{R}
$$

Substituting all of the variables we obtain the following form of expression (2): 


$$
W=R \cdot \lambda \cdot \rho \cdot\left(A_{p}+A_{t r}+A_{i}\right)+\frac{\left(t_{i n}-t_{\text {ext }}\right) \cdot n \cdot m \cdot z}{R} \cdot T
$$

The optimality criterion is the minimum of the energy costs.

Receiving the following equitation:

$$
\frac{\partial W}{\partial R}=0
$$

Solving for R, we obtain:

$$
R=R_{\text {opt }}=\sqrt{\frac{\left(t_{\text {in }}-t_{\text {ext }}\right) \cdot n \cdot m \cdot z \cdot T}{\lambda \cdot \rho \cdot\left(A_{p}+A_{t r}+A_{i}\right)}}
$$

Thus, taking from structural considerations any constant layers of the building envelope with its known parameters (layer thickness, thermal conductivity), it is possible to calculate the optimal thickness of the selected insulation material.

Let us consider the effect of the two main variables for this model (the degree-days $\left(D D=\left(t_{\text {in }}-t_{\text {ext }}\right) \cdot z\right)$ and primary energy consumption per unit - the unit cost of thermal energy $\left.\left(A=A_{p}+A_{t r}+A_{i}\right)\right)$ they have on the value $R_{\text {opt }}$. To do this, we evaluate the dependency graphs:

$$
R_{o p t}=f(\mathrm{DD})
$$

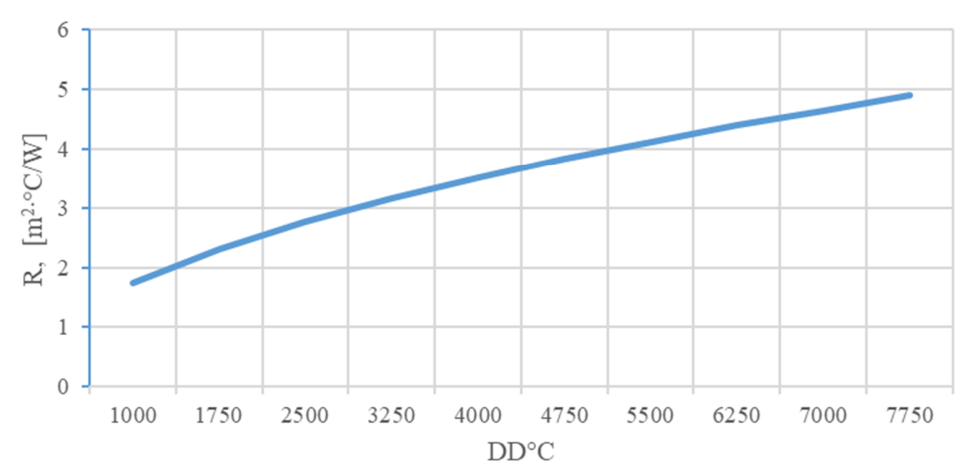

Fig.2. Change in thermal resistance $R$ depending on the degree days DD

$$
R_{\text {opt }}=f(\mathrm{~A})
$$

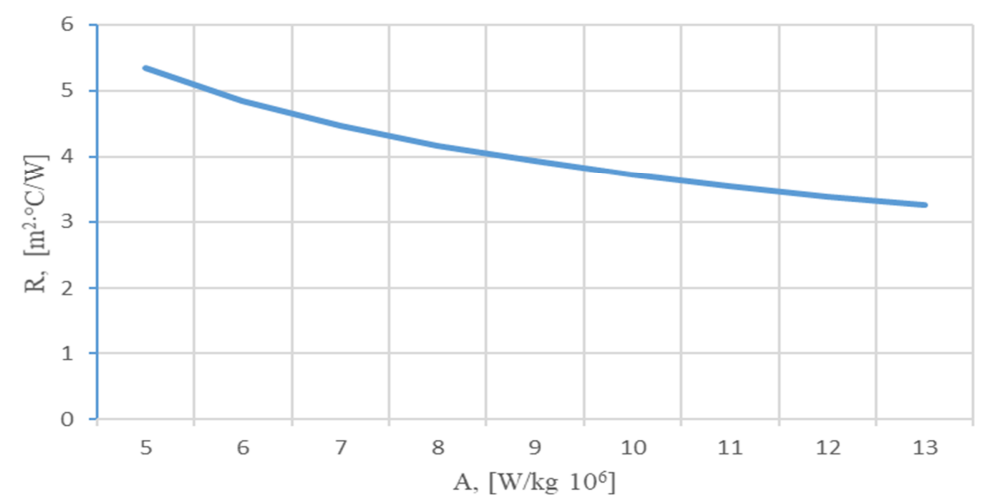

Fig.3. Change in thermal resistance $R$ depending on the unit energy cost of insulation material $A$ 
And compare the inclination angles of the tangents to the lines in the graphs:

$$
\begin{aligned}
& \operatorname{tg} \alpha_{1}=\frac{\partial R_{o p t}}{\partial D D} \\
& \operatorname{tg} \alpha_{2}=\frac{\partial R_{o p t}}{\partial A}
\end{aligned}
$$

For calculations simplicity we represent expression (6) in the following form:

$$
\begin{array}{r}
R_{o p t}=B \cdot \sqrt{\frac{D D}{A}} \\
\text { where } B=\sqrt{\frac{n \cdot m \cdot T}{\lambda \cdot \rho}}
\end{array}
$$

Then:

$$
\begin{aligned}
& \operatorname{tg} \alpha_{1}=\frac{B}{2 \cdot \sqrt{A \cdot D D}} \\
& \operatorname{tg} \alpha_{2}=\frac{-B \cdot \sqrt{D D}}{2 A \cdot \sqrt{A}}
\end{aligned}
$$

Under the conditions of this problem $A<D D$, we replace:

$$
D D=A \cdot x
$$

where $x$ is a certain number different for each values of the function parameters, $x>1$. It gives:

$$
\begin{array}{r}
\left|\operatorname{tg} \alpha_{1}\right|=\frac{B}{2 \cdot A \cdot \sqrt{x}} \\
\left|\operatorname{tg} \alpha_{2}\right|=\frac{B \cdot \sqrt{x}}{2 A} \\
\left|\operatorname{tg} \alpha_{1}\right|<\left|\operatorname{tg} \alpha_{2}\right|
\end{array}
$$

Thus, from analysing the mathematical model received, we can conclude that the primary energy consumption parameter affects the value of the optimal thermal resistance $R_{\text {opt }}$ to a greater extent than the degree-days value.

\subsection{Choosing the optimal material for the insulating layer}

Considering expression 6 , substitute the numerator of this expression with the constant $a$; since all the variables included in the numerator depend only on the region of construction, and do not depend on the choice of insulation.

$$
a=n \cdot m \cdot z \cdot\left(t_{\text {in }}-t_{\text {ext }}\right)
$$

The product of the thermal conductivity coefficient, material density and the energy cost of $1 \mathrm{~kg}$ of insulation, in the denominator, is represented in the variable $K$, which indicates a reasonable rate of energy consumption:

$$
K=\lambda \cdot \rho \cdot A
$$


Having made all of the substitutes mentioned above, we obtain the following form of expression (6):

$$
R_{\text {opt }}=\sqrt{\frac{a}{K}}
$$

Rearranging gives:

$$
K=\frac{a}{R_{o p t}^{2}}
$$

Since the value of thermal resistance cannot be lower than its standard value, we introduce the following restriction:

$$
K=\frac{a}{R_{o p t}^{2}} \leq \frac{a}{R_{n}^{2}}
$$

where $R_{n}$ is the standard (normative) value of thermal resistance, $\frac{m^{2} \cdot{ }^{\circ} \mathrm{C}}{W}$.

This mathematical model allows evaluating the energy feasibility of using some particular material in the conditions of a particular region.

\section{Results and Discussion}

An example of calculation according to the formula (6) obtained in paragraph 2.1 is presented in table 3. It is based on the parameters of Moscow and St. Petersburg and ROCKWOOL stone wool insulation material $\left(\lambda=0.041 \frac{\mathrm{W}}{\mathrm{m} \cdot{ }^{\circ} \mathrm{C}}\right)$. The selection of the energyoptimal insulation thickness was made separately for the following structural layers: aerated concrete $\left(0,2 \mathrm{~m}\right.$ thick with a coefficient of thermal conductivity of $\left.\lambda=0.096 \frac{\mathrm{W}}{\mathrm{m} \cdot{ }^{\circ} \mathrm{C}}\right)$ and brickwork $\left(0,250 \mathrm{~m}\right.$ thick with a coefficient of thermal conductivity of $\left.\lambda=0.47 \frac{\mathrm{W}}{\mathrm{m} \cdot{ }^{\circ} \mathrm{C}}\right)$.

Table 2. Calculated insulation thickness

\begin{tabular}{|c|c|c|c|c|c|}
\hline & \multirow{2}{*}{$R_{n} \frac{m^{2 .}{ }^{\circ} \mathrm{C}}{W}$} & \multirow{2}{*}{$R_{\text {opt }, \frac{m^{2 .} \mathrm{o} C}{W}}$} & $\Delta R, \%$ & \multicolumn{2}{|c|}{ Insulation thickness for } \\
\cline { 5 - 7 } & 3.056 & 3.820 & 25.0 & 0.065 & 0.128 \\
\hline St. Petersburg & 3.062 & 3.827 & 24.9 & 0.065 & 0.129 \\
\hline Moscow & 2.629 & 3.291 & 25.2 & 0.043 & 0.107 \\
\hline Rostov-on-Don & 2.677 & 3.353 & 25.3 & 0.046 & 0.109 \\
\hline Pyatigorsk & 3.276 & 4.065 & 24.1 & 0.075 & 0.138 \\
\hline Nizhny Novgorod & 3.640 & 4.443 & 22.1 & 0.090 & 0.154 \\
\hline Novosibirsk & 3.569 & 4.371 & 22.5 & 0.087 & 0.151 \\
\hline Khabarovsk & 3.433 & 4.231 & 23.2 & 0.082 & 0.145 \\
\hline Yekaterinburg & & & & & brickwork, $\mathrm{m}$ \\
\hline
\end{tabular}


As can be seen from the data provided in the table, the optimal thermal resistance of the structure exceeds the standard value by an average of $25 \%$.

Using formula (13) obtained in clause 2.2, the feasibility of using some specific insulation materials was assessed using the conditions of the city of St. Petersburg companies as an example.

$$
K_{\text {opt }}=77.9
$$

Considering the standard value of thermal resistance for St. Petersburg $R_{n}=3.06 \frac{\mathrm{m}^{2} \cdot{ }^{\circ} \mathrm{C}}{\mathrm{W}}$, we have the following restriction:

$$
K \leq 133.14
$$

Basing on the information on primary energy consumption got from the manufacturer it is possible to choose an optimal insulating material under the certain climatic conditions.

\section{Conclusions}

1. A mathematical model for the energy optimal thermal resistance value of the entire building envelope structure was developed. The key factors to influence this value are: the region degree-days and the energy consumption rate for the production, transportation and installation of the insulation material. . It allows calculating the relevant thickness of the selected insulation material under any climatic and economic conditions with any constant layers of the building envelope taken from structural considerations.

2. If considering the disadvantage of the model, we can remark that is requires the data, which sometimes has no public access.

3. On the other hand, determination the thermal resistance through energy consumption can serve as a more objective assessment when comparing the level of building thermal protection in different countries, due to the fact that it doesn't depend on economic situation of the region. Using this approach allows to evaluate the savings via the energy amount, which can also serve as an objective assessment because of being treated the same way in different regions.

4. A method of insulating material choosing was also derived from the model. This is a product of three variables: the unit energy cost, material density and thermal conductivity of the material. It allows to assess the existing market offers for the insulation materials according to the primary energy conservation point of view.

\section{References}

1. L.N. Danilevski, S.L. Danilevsky. Magazine of Civil Engineering 5,. 49-61 (2017). DOI: 10.18720/MCE.73.5.

2. E.A. Statsenko, A.F. Ostrovaia, T.A. Musorina, M.I. Kukolev, M.R. Petritchenko. Magazine of Civil Engineering 8, 86-91 (2016). DOI: 10.5862/MCE.68.9.

3. T. Kisilewicz, MDPI. Sustainability. Pp. 1-20 (2019). DOI: 10.3390/su11041061

4. H. A. Gabbar, F. Musharavati, S. Pokharel. Energy Procedia. 6th International Conference on Sustainability in Energy and Buildings 1, 666-675 (2014). DOI: 10.1016/j.egypro.2014.12.430 
5. B. Shao, X. Liu. Conference on Advanced Machine Learning Technologies and Applications, 837-844 (2020). DOI: 10.1007/978-3-030-14118-9_82

6. A.S. Gorshkov, N.A. Sokolov. Magazine of Civil Engineering 7, 7-14 (2013). DOI: 10.5862/MCE.42.2

7. M.V. Knatko, A.S. Gorshkov. Magazine of Civil Engineering 2, 50-53 (2008). DOI: 10.18720/MCE.2.8

8. A. S. Gorshkov, N.I. Vatin, P.P. Rymkevich, O.O. Kydrevich. Magazine of Civil Engineering 2, 65-75 (2018). DOI: 10.18720/MCE.78.5

9. L. Aditya, T.M.I. Mahlia, B. Rismanchi, H.M. Ng, M.H. Hasan, H.S.C. Metselaar, Oki Muraza, H.B. Aditiya. Renewable and Sustainable Energy Reviews 73, 1352-1365 (2017). DOI: 10.1016/j.rser.2017.02.034

10. L. Zhang, Z. Liu, C. Hou, J. Hou, D. Wei, Y. Hou. Case Studies in Thermal Engineering 14, 1-9 (2019). DOI: 10.1016/j.csite.2019.100410

11. O.V. Averianova. Magazine of Civil Engineering 5, 53-60 (2011). DOI: 10.5862/MCE.23.9

12. M. Zekic-Susac, M. Knezevic, R. Scitovski. DInternational Workshop on Soft Computing Models in Industrial and Environmental Applications, 101-110 (2020). DOI: 10.1007/978-3-030-20055-8_10

13. P. Morano, P. Rosato, F. Tajani, F. Di Liddo. Values and Functions for Future Cities, 73-88 (2019). DOI: 10.1007/978-3-030-23786-8_5

14. J. O. Olaussen, A. Oust, J.T. Solstad, L. Kristiansen. MDPI. Energies, 1-14 (2019). DOI: $10.3390 /$ en12183563

15. R. Dylewski. MDPI. Energies, 1-14 (2019). DOI: 10.3390/en12183415

16. M. F. Alsayed, R.A. Tayeh. Journal of Building Engineering 22, 101-112 (2019). DOI: 10.1016/j.jobe.2018.11.018

17. M. Ozel. Applied Thermal Engineering 31, 3854-3863 (2011). DOI: 10.1016/j.applthermaleng.2011.07.033

18. T. Gorokhova, L. Pushkareva, M. Sredin, M. Pushkarev. E3S Web of Conferences 135, 04069 (2019). https://doi.org/10.1051/e3sconf/201913504069

19. Y. Tamene, L. Serir. International Journal of Heat and Technology 37(1), 219-228 (2019). DOI: 10.18280/ijht.370127 